\title{
LAMINAÇÃO \\ AÇOS MICROLIGADOS AO Ti: OPTIMIZAÇÃO DE PRODUTIVIDADE NA LAMINAÇÃO A FRIO DA CSN*
}

\section{Resumo}

Rodrigo Rocha de Meira ${ }^{1}$

Hugo Shokychi Toshimitsu ${ }^{2}$

Marcelo Geraldo Rocha Milagres ${ }^{3}$

Augusto Cesar Lacerda de Oliveira ${ }^{4}$

Luiz Fernando Witte Borges 5

Flavia Tereza dos Santos Tolomelli6

O laminador de tiras a frio $n^{\circ} 3$ da CSN apresentava perdas de produtividade ao processar aços de elevada resistência microligados, com limite de escoamento mínimo igual a $340 \mathrm{MPa}$, dotados de largura superiores a $1400 \mathrm{~mm}$. Devido à crescente demanda do mercado automotivo relativa a esta família de aços, tornouse necessário um estudo para optimizar a produtividade do equipamento e não desestabilizar o fornecimento aos clientes. O estudo consistiu em testar parâmetros de processo alternativos, objetivando abastecer o laminador de tiras a frio com bobinas laminadas a quente dotadas de resistência mecânica ligeiramente menor, para promover maior estabilidade operacional no equipamento a partir da redução das cargas de laminação. As alterações propostas resultaram no aumento de produtividade do laminador de tiras a frio, sem comprometer as características mecânicas do produto final.

Palavras-chave: Aços de alta resistência; Composição química; Temperatura de bobinamento; Indústria automotiva.

\section{Ti MICROALLOYED STEELS: OPTIMIZATION OF PRODUCTIVITY IN COLD ROLLING CSN}

\section{Abstract}

The CSN's tandem cold mill presented in recent years, reduced productivity indexes when processing microalloyed high strength steels with minimum yield strength equal to $340 \mathrm{MPa}$, when the width exceeding $1400 \mathrm{~mm}$. Due to increasing demand from the automotive market on this steels families, it became necessary a study to optimize the equipment productivity and not disrupt supplies to customers. The study was to test alternative process parameters, aiming to supply the tandem cold mill with hot rolled coils endowed with slightly lower mechanical resistance, to promote greater stability in equipment operation through the reduction of rolling loads. The proposed changes increased the tandem cold mill productivity, without compromising the mechanical properties of the final product.

Keywords: High strength steels; Chemical composition; Coiling temperature; Automotive industry.

\footnotetext{
1 Engenheiro Metalúrgico, MSc., CQE., Engenheiro de Processos de Laminação da CSN.

2 Engenheiro Metalúrgico, Engenheiro de Redução a Frio da CSN;

${ }^{3}$ Engenheiro Metalúrgico, Engenheiro de Processos de Laminação da CSN;

${ }^{4}$ Engenheiro Metalúrgico, DSc., Engenheiro de Desenvolvimento de Produtos da CSN.

5 Técnico de Desenvolvimento Especialista de Redução a Frio da CSN.

${ }^{6}$ Engenheiro Metalúrgico, MSc., Engenheiro de Desenvolvimento de Produtos da CSN.
}

* Contribuição técnica ao $51^{\circ}$ Seminário de Laminação - Processos e Produtos Laminados e Revestidos, 28 a 31 de outubro de 2014, Foz do Iguaçu, PR, Brasil. 


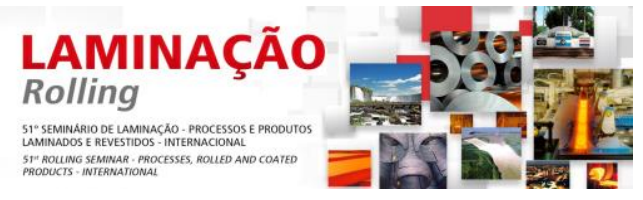

Tabela 1. Composição química dos aços estudados

\begin{tabular}{ccc} 
& GRUPO 1 & GRUPO 2 \\
\hline & MÁX. & MÁX. \\
\hline$\% C$ & 0,080 & 0,070 \\
\hline$\% \mathrm{Mn}$ & 0,700 & 0,650 \\
\hline$\% P$ & 0,025 & 0,020 \\
\hline$\% S$ & 0,015 & 0,010 \\
\hline$\% \mathrm{Ti}$ & 0,040 & 0,037 \\
\hline
\end{tabular}

Trinta e cinco bobinas a quente (BQs) foram bobinadas à temperatura visada de $570^{\circ} \mathrm{C}$ e dez bobinas foram laminadas à temperatura visada de $590^{\circ} \mathrm{C}$, e o efeito nas cargas de laminação médias das cinco cadeiras foi verificado posteriormente. A figura 1 descreve a variação da TB.

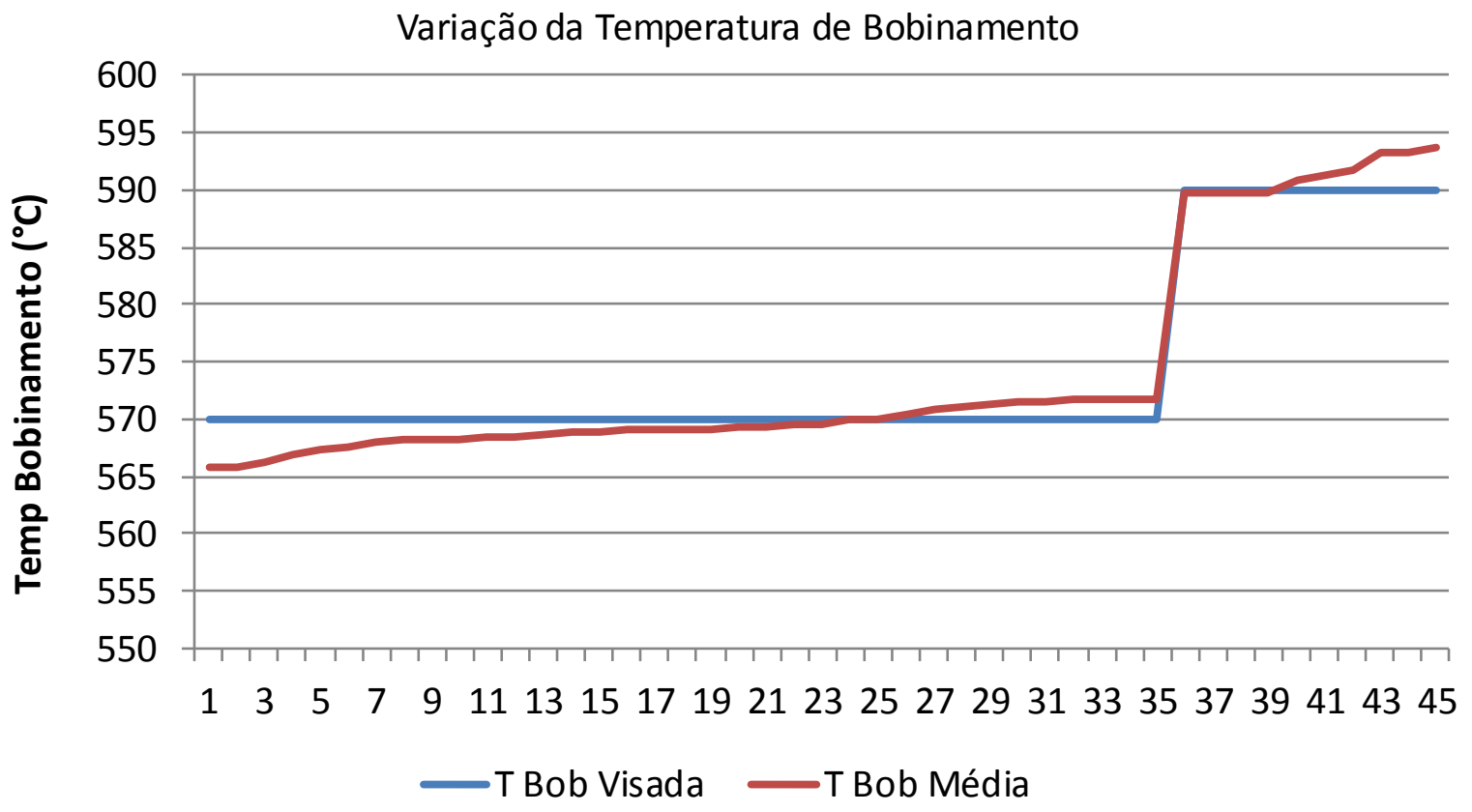

Figura 1. Variação da temperatura de bobinamento em BQs.

Em relação ao diâmetro dos cilindros de trabalho, foram processadas $1810 \mathrm{t}$ de bobinas a quente do grupo 1, utilizando-se as medidas 517, 539, 550, 551 e $557 \mathrm{~mm}$ no diâmetro dos cilindros de trabalho da cadeira 1 do laminador a frio. $O$ efeito do diâmetro de cilindros foi avaliado conforme a carga de laminação observada na cadeira 1. Os demais parâmetros de processo não foram alterados.

Para se estudar o efeito da composição química, foram processadas 1280 t do aço em estudo utilizando-se as composições químicas dos grupos 1 e 2 da tabela 1, destinadas à produção de bobinas a frio galvanizadas. Com o objetivo de reduzir a resistência mecânica das $B Q s$, foi proposta a composição química do grupo 2 com base em simulações a partir de um modelamento matemático preditivo de propriedades mecânicas, utilizando-se as variáveis de entrada composição química, espessura do esboço laminado a quente e as temperaturas de acabamento e bobinamento. Este modelo matemático forneceu a predição de um limite de

* Contribuição técnica ao $51^{\circ}$ Seminário de Laminação - Processos e Produtos Laminados e Revestidos, 28 a 31 de outubro de 2014, Foz do Iguaçu, PR, Brasil. 


\section{RESULTADOS E DISCUSSÃO}

\subsection{Efeito da Temperatura de Bobinamento}

Conforme a variação da TB descrita na figura 2, a figura 3 discrimina o efeito deste parâmetro na carga de laminação do laminador a frio.

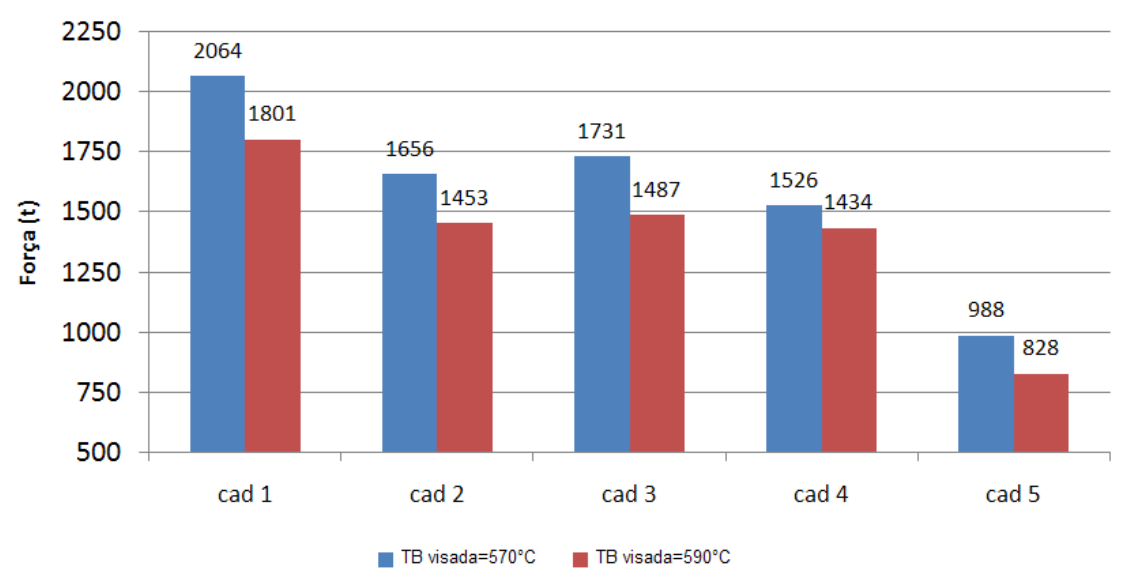

Figura 3. Efeito da variação da TB nas cargas de laminação médias do laminador a frio.

Nota-se na figura 3 uma redução das cargas de laminação das cinco cadeiras do laminador. Teoricamente, o material processado com maior temperatura de bobinamento possui maior deformabilidade, em decorrência do coalescimento acentuado dos precipitados de titânio presentes na matriz ferrítica. Apesar da redução das cargas de laminação em todas as cadeiras, não foi observado o esperado aumento de produtividade do laminador a frio. Todas as BQs foram provenientes do grupo 1.

\subsection{Efeito do Diâmetro dos Cilindros de Trabalho da Cadeira 1}

A figura 4 mostra o efeito da variação do raio dos cilindros de trabalho $(R)$ nas cargas de laminação da cadeira 1, utilizando-se duas espessuras de BQ: 2,70 e 2,81 $\mathrm{mm}$. Para as duas espessuras de $B Q$ testadas, notam-se menores valores de carga na utilização de menores valores de R. Isto porque, quanto menor $R$, menor é a área de contato entre o cilindro e a chapa, resultando em menores esforços de laminação por parte do laminador, conforme equação 1 [6].

$$
\mathbf{P} / \mathbf{w}=\mathbf{S} \sqrt{\mathbf{R} \Delta \mathbf{h}}(1)
$$

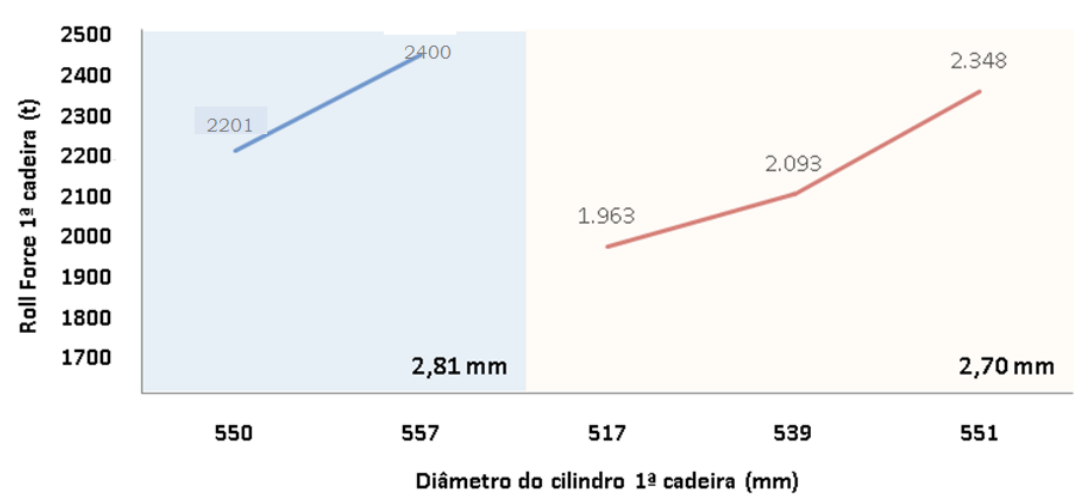

Figura 4. Efeito da variação de $\mathrm{R}$ nas cargas de laminação médias do laminador a frio.

* Contribuição técnica ao $51^{\circ}$ Seminário de Laminação - Processos e Produtos Laminados e Revestidos, 28 a 31 de outubro de 2014, Foz do Iguaçu, PR, Brasil. 


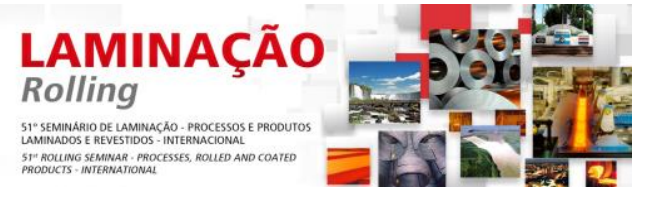

Onde a razão $\mathrm{P} / \mathrm{w}$ é carga de laminação por unidade de largura da chapa, $\mathrm{S}$ a tensão média de escoamento do material no estado plano de deformação e $\Delta \mathrm{h}$ a diferença entre as espessuras final e inicial da chapa laminada.

Uma vez que os maiores esforços de laminação são observados na cadeira 1, os cilindros de menor diâmetro foram testados somente nesta cadeira. Apesar da redução de cargas observada na primeira cadeira, o esperado aumento de produtividade não pôde ser observado, principalmente pela pequena disponibilidade de pares de cilindro com menor R. Neste caso, seria necessária uma adequação desta disponibilidade ao programa de produção do laminador, o que nem sempre é possível.

\subsection{Efeito da Composição Química}

Após a ocorrência dos fenômenos de precipitação na composição química do grupo 2, a situação de cada elemento em solução após os efeitos das combinações com Ti e Al são:

- Todo o N é consumido na precipitação de TiN.

- O S é consumido parcialmente para se formar o precipitado TiS.

- Apenas 14 ppm de C são consumidos na formação do precipitado TiC.

Conforme a literatura consultada, TiN e TiS são precipitados com diâmetro médio consideravelmente maior que o do $\mathrm{TiC}$, o que resulta em modesta contribuição para o mecanismo de endurecimento por precipitação. Presume-se que o endurecimento que ocorre no aço em estudo pode ser creditado às presenças de $C, M n, P$ e $S$ em solução sólida, além do endurecimento por precipitação de TiC.

A tabela 2 representa uma análise comparativa entre as propriedades mecânicas das BQs provenientes dos grupos 1 e 2 (cp base $80 \mathrm{~mm}$, direção transversal).

Tabela 2. Propriedades mecânicas de BQ referentes aos grupos 1 e 2 .

\begin{tabular}{cccc|ccc} 
& \multicolumn{3}{c|}{ Grupo 1 } & \multicolumn{3}{c}{ Grupo 2 } \\
\cline { 2 - 7 } & LE (MPa) & LR (MPa) & AL (\%) & LE (MPa) & LR (MPa) & AL (\%) \\
\cline { 2 - 7 } & 439 & 529 & 23 & 382 & 516 & 27 \\
\hline & 453 & 532 & 25 & 426 & 520 & 24 \\
\hline média & 446 & 531 & 24 & 404 & 518 & 26 \\
\hline $\mathrm{dp}$ & 10 & 2 & 1 & 31 & 3 & 2 \\
\hline
\end{tabular}

De acordo com os resultados acima, nota-se maior média de LE e LR do grupo 1 em relação ao grupo 2, bem como menor média de $A L$ do grupo 1 em relação ao grupo 2. Tais resultados estão conforme o esperado, visto que a composição química do grupo 2 é menos "carregada" em relação ao grupo 1. A figura 5 mostra a microestrutura das BQs referentes a cada grupo. Não foi observada a diferença entre os tamanhos de grão ferríticos. 


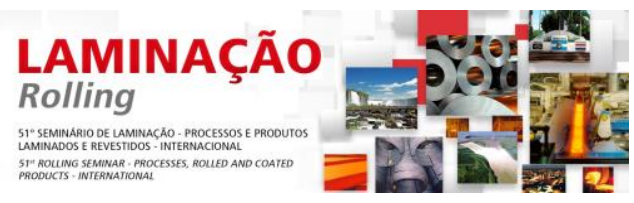

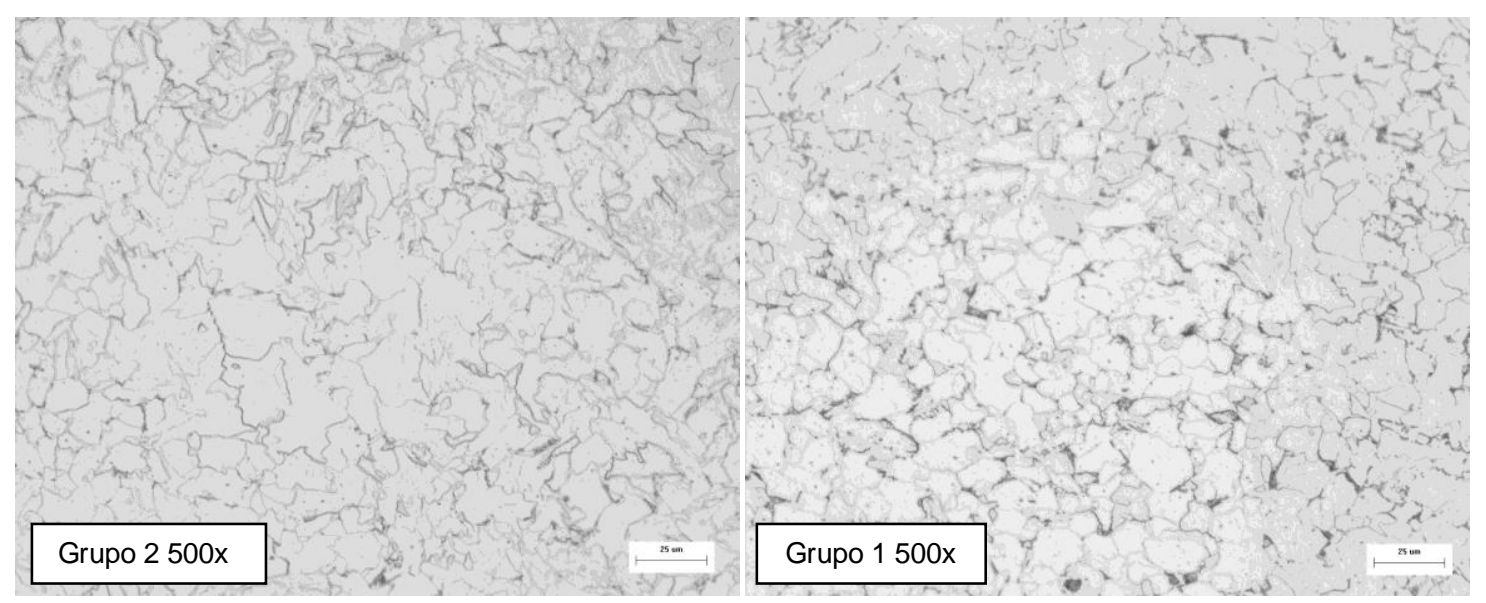

Figura 5. Microestrutura de BQ dos aços estudados.

A figura 6 mostra o efeito da composição química nas cargas de laminação das cinco cadeiras do laminador a frio.

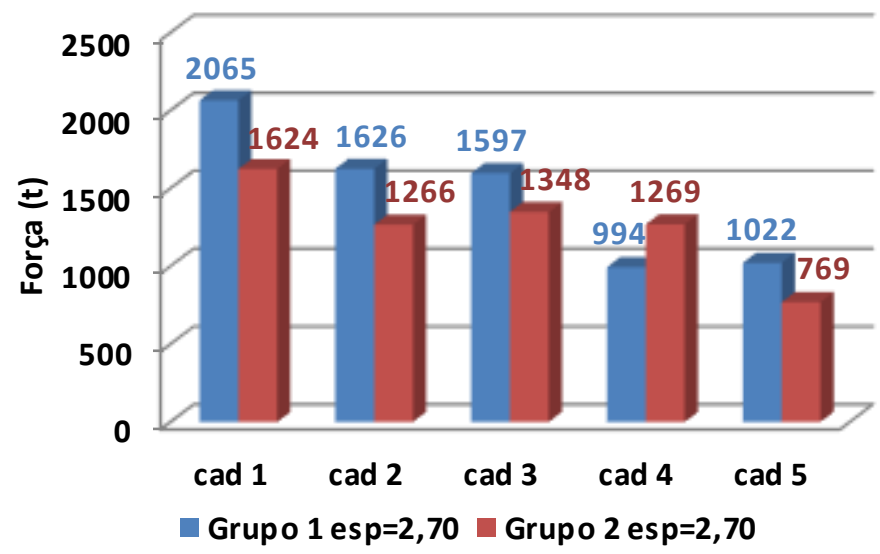

Figura 6. Efeito da composição química nas cargas de laminação médias do laminador a frio.

Nota-se na figura 6 que as cargas de laminação obtidas no material do grupo 2 foram menores que as relativas ao grupo 1 , exceto na cadeira 4 , onde 0 modelo matemático do laminador necessitará de pequenos ajustes, pois a carga obtida não condiz com o resultado esperado.

Considerando o que foi mostrado na tabela 3 e na figura 5, pode-se inferir que o aço do grupo 2 possui menor resistência mecânica que aço do grupo 1. Estes resultados traduzem condições operacionais mais confortáveis no processamento do aço do grupo 2, dando ao equipamento melhores oportunidades de melhoria de produtividade, conforme a figura 7 .

* Contribuição técnica ao $51^{\circ}$ Seminário de Laminação - Processos e Produtos Laminados e Revestidos, 28 a 31 de outubro de 2014, Foz do Iguaçu, PR, Brasil. 

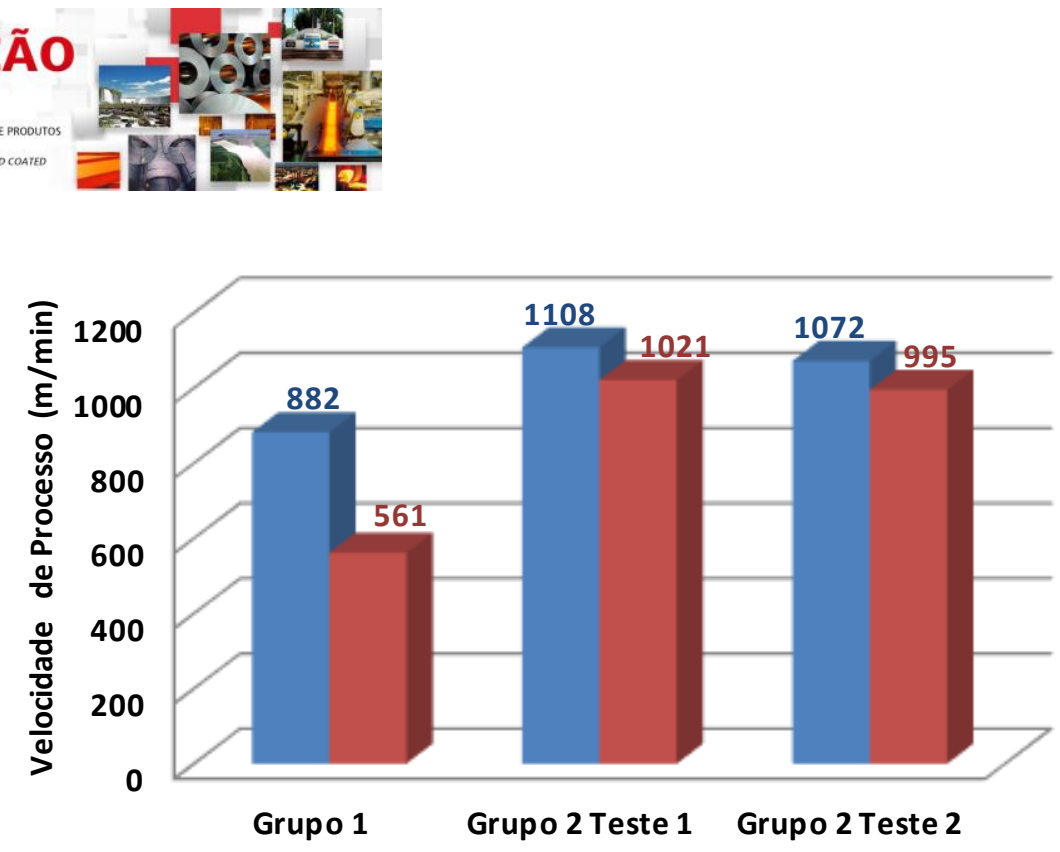

Figura 7. Efeito da composição química na produtividade do laminador a frio.

Nota-se um incremento médio de $90 \%$ na velocidade de processo do laminador, indicando expressivo ganho de produtividade ao se processar o aço proveniente da composição química do grupo 2.

$\mathrm{Na}$ figura 8 é mostrada uma análise de variância - 1 fator, que compara os resultados das propriedades mecânicas $L E$, $L R$ e $A L$ do produto final, proveniente dos grupos 1 ou 2.
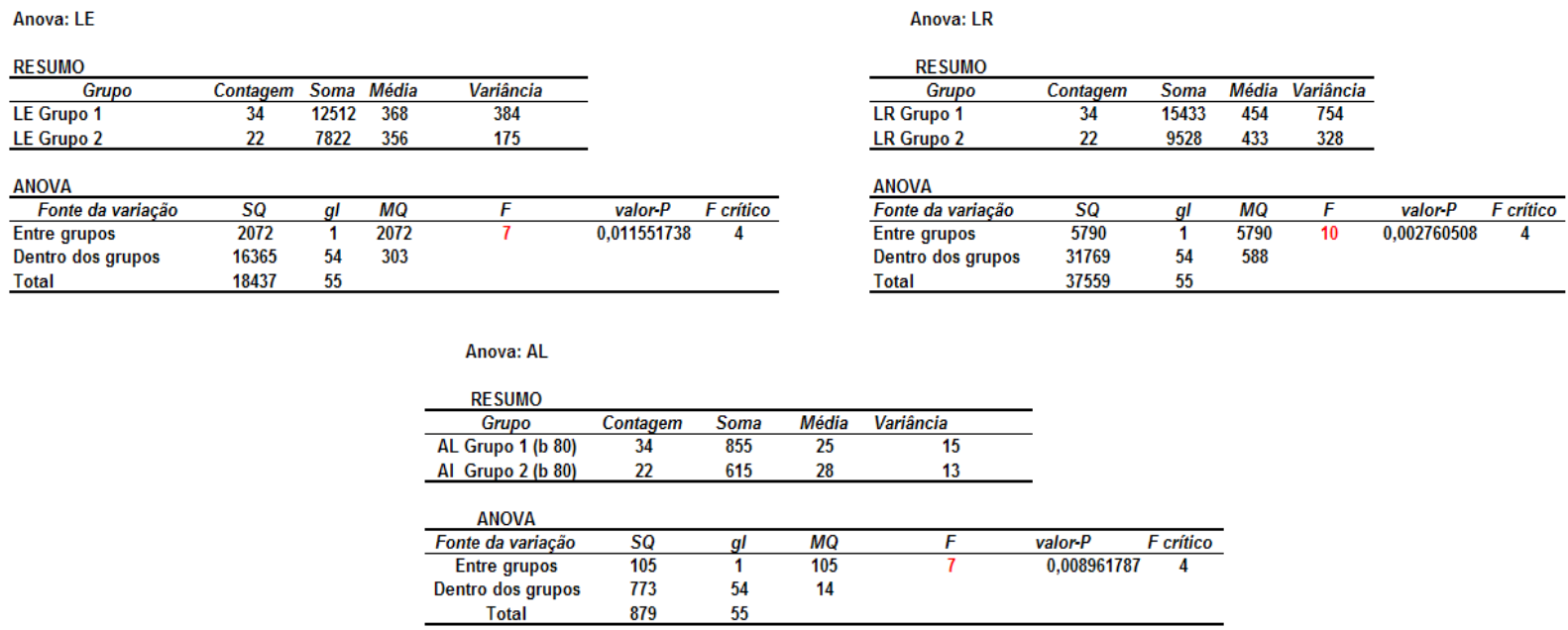

Figura 8. Efeito da composição química nas propriedades mecânicas do produto final.

A partir dos resultados da figura 8, pode-se afirmar que os produtos provenientes dos grupos 1 e 2 possuem propriedades mecânicas de produto diferentes entre si, mesmo atendendo os requisitos das principais normas automotivas dos aços da família HSLA340. Os produtos do grupo 2 possuem características mecânicas que indicam maior conformabilidade em relação ao grupo 1.

\section{CONCLUSÃO}

A alteração da temperatura de bobinamento foi eficaz na redução de cargas do laminador a frio, no entanto não se caracterizou como fator decisivo para o aumento de produtividade deste equipamento.

* Contribuição técnica ao $51^{\circ}$ Seminário de Laminação - Processos e Produtos Laminados e Revestidos, 28 a 31 de outubro de 2014, Foz do Iguaçu, PR, Brasil. 
